\title{
Model of Filling the Internal Structure of Workpiece with Curved Layers for 3D Printing
}

\author{
A.N. Grechukhin ${ }^{1, a^{*}}$ and V.V. Kuts ${ }^{1, b}$ \\ ${ }^{1}$ Southwest State University, 50 Years of October St., 94, Kursk, Russia \\ a agrechunin@mail.ru, buc-vadim@yandex.ru
}

Keywords: Additive Technologies, Layer-By-Layer Synthesis, Curved Layer

\begin{abstract}
This paper presents a solution to the problem of filling the internal structure of the workpiece with curve layer in 3D printing. A generalized model of filling the internal structure of workpiece with curve layer is designed. The results are presented for solving the problem on the example of curved layers of a conical shape with filling along a helical line. The research results can be in demand in the development of algorithms and software for technological equipment. They allow to ensure the formation of the internal structure of products in curved layers during 3D printing.
\end{abstract}

\section{Introduction}

The development of additive technologies is aimed at expanding the area of their application for solving various problems, including for obtaining structures with increased physical and mechanical properties. FDM printing technology is one of the ways to create such structures by filling the internal structure of products with curved layers formed by sections of various geometric shapes [1-9].

\section{Relevance of the research topic}

Research carried out by research teams [11-15] shows that the formation of the internal structure of products with curvilinear layers makes it possible to obtain structures with higher strength characteristics compared to filling with flat layers. The development of models, algorithms and software is an urgent task. It allows curve layers to form the internal structure of the product during $3 \mathrm{D}$ printing.

The preparation includes the following stages in printing using FDM technology in general: the separation occurs of a three-dimensional digital model, as a rule, in STL format, which is a list of coordinates of the vertices of triangular faces (facets) forming a surface into many curvilinear layers; the task is to select the trajectory of the extruder relative to the part; finding is carried out by areas of filling with material in accordance with the shape of the part [16-22]. The layer is applied one by one until the object is completely built.

An urgent task is to determine the trajectories of movement of the extruder, as well as areas of filling with material during the formation of the internal structure of products with curved layers.

\section{Materials and methods for solving the issue}

Work [10] proposes a technique for dividing a three-dimensional model into curved layers for 3D printing, for example, a conical shape (fig. 1). 


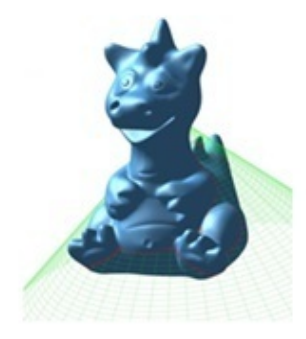

a)

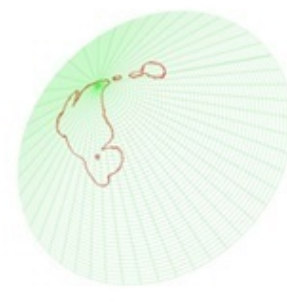

b)

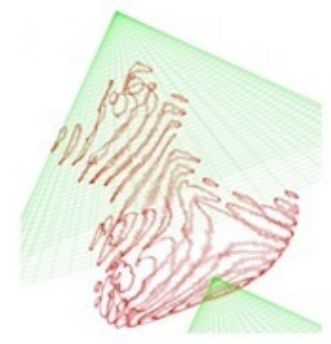

c)

Fig. 1. The section of the original part is represented by a cone: a) the position of the original part and the cutting cone; b) facets forming the intersection of the secant cone with the original part; c) a lot of sections of the original part with a cone

The task is to divide the model into curved conical layers for 3D printing by forming an array of facet numbers $(M)$ that have intersection points with a secant conical surface. It is described by the equation:

$$
r_{0}(u, v)=\left[\begin{array}{l}
\sin u \cdot \sin (2 \varphi) v ; \\
-\cos u \cdot \sin (2 \varphi) v ; \\
\cos \left(2 \varphi_{1}\right) v+v+Z_{0}
\end{array}\right],
$$

where $u, v$-cone parameters; $\varphi$ - half the cone angle; $Z_{0}$ - cone vertex coordinate.

In order to prepare for the printing of FDM technology, the following tasks are required. It consists in setting the trajectories of the extrude. Such trajectories can be described by different spatial curves, and their points are located on the cutting surface of the cone.

In particular, when dividing the model into conical layers, the trajectory can be set by the movement of the extruder by a conical helical line. It is described by the equation:

$$
r(v)=\left[\begin{array}{l}
\cos \left(\frac{k \cdot\left(v-Z_{0}\right) \cdot 2 \pi}{P}+U_{n}\right) \cdot\left(v-Z_{0}\right) \cdot \operatorname{tg} \varphi \\
\sin \left(\frac{k \cdot\left(v-Z_{0}\right) \cdot 2 \pi}{P}+U_{n}\right) \cdot\left(v-Z_{0}\right) \cdot \operatorname{tg} \varphi \\
v \\
1
\end{array}\right],
$$

where $v$ - screw parameter; $Z_{0}$ - cone vertex coordinate; $\varphi$ - half the cone angle; $P$ - screw pitch; $U_{n}$ - Initial twist angle of helix; $k$ - screw line torsion direction: $k=-1$ - clockwise, $k=1-$ counterclockwise.

It is necessary to create an array of points to determine the areas of filling of the spatial curve (an array of parameters), which determines the trajectories of the extruder, which are the intersection points of the specified spatial curve with the plane of facets, the numbers of which belong to the array $M$. 


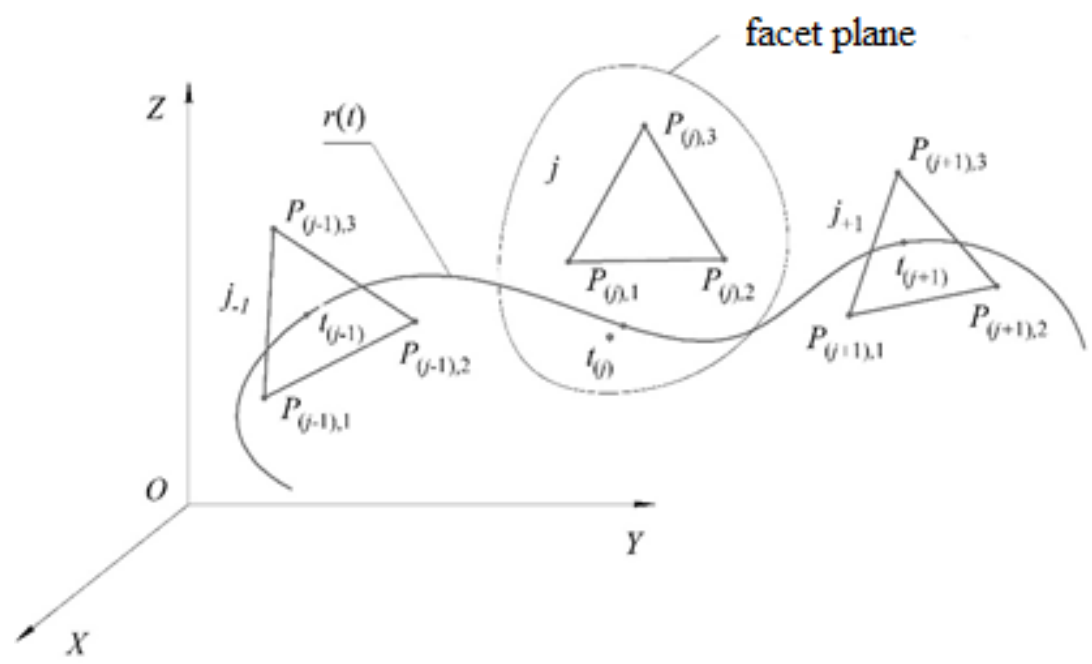

Fig. 2. Defines an intersection that represents a space curve and a face plane

Determination of the necessary intersection points of a given spatial curve with the facet planes is necessary for each facet included in the array $M$ (fig. 2) by solving the equation:

$$
A_{j} \cdot r(t) \cdot k_{j}=0
$$

regarding parameter $t$, where $A_{j}$ - matrix of transition to the coordinate system, built on the points of the $j$-th facet, whose coordinate center is located at the point $P_{j 1}$, and the $Z_{j}$ axis is perpendicular to the facet plane. Fig. 3 shows a scheme for determining the point of intersection of a spatial curve with a facet plane

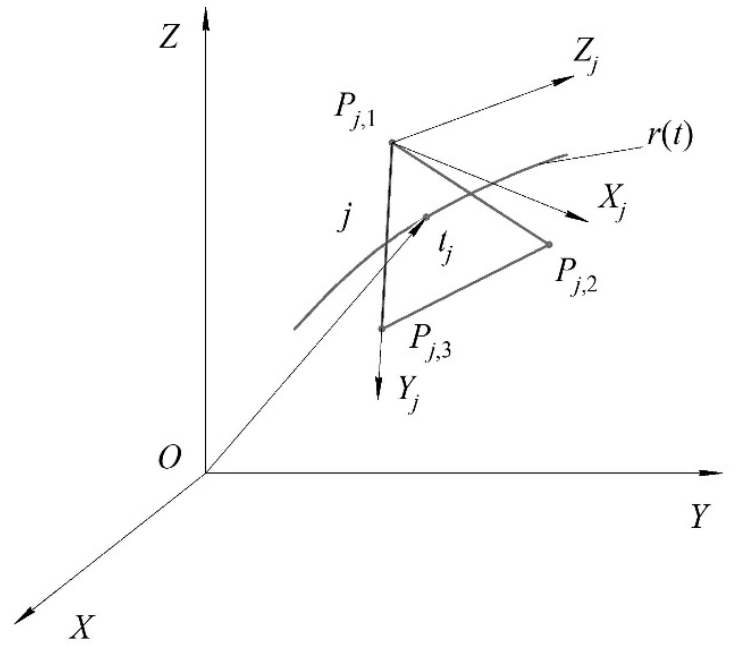

Fig. 3. The diagram shows the definition of the intersection point of the spatial curve with the facet plane

The set $T$ of values of the parameter $t_{k}$ can be found by solving the equation. There is a need to select from the set $T$ subset of parameters for which the curve $r(t)$ as intersection points located inside the facet. Known methods [23] can be used to solve this problem.

We define the areas of filling with material by grouping the parameters of the curve $r(t)$, corresponding to the points of intersection of the curve with all facets. To do this, it is necessary 
to construct a variational series of parameters $t_{k}$, with properties $t_{1} \leq t_{2} \leq \ldots \leq t_{k} \leq \ldots \leq t_{k-1} \leq t_{k}$ and form an array of pairs of parameters $\left[t_{1}, t_{2}\right],\left[t_{3}, t_{4}\right], \ldots\left[t_{k-1}, t_{k}\right]$. The obtained pairs of parameters $t_{k}$ will correspond to the sections of the extruder movement trajectories, on which filling with the material takes place.

For example, a diagram is presented for determining the points of intersection of a helical line with a certain body in fig. 4 .

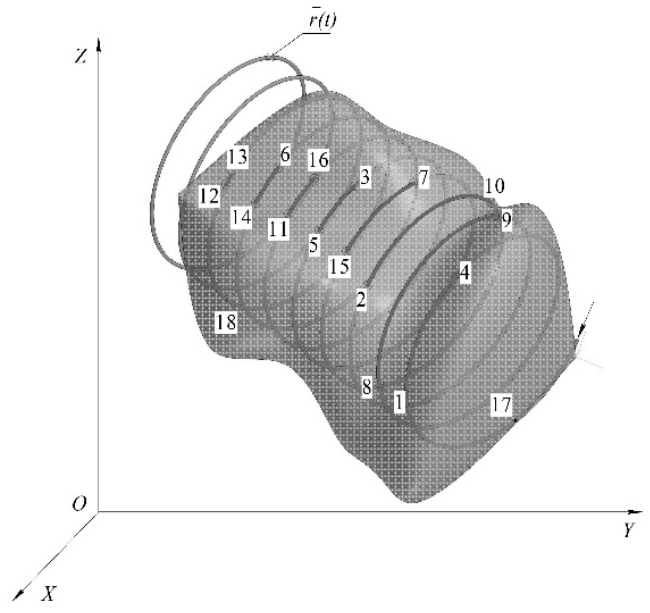

Fig. 4. The diagram shows the intersection of a helix with a certain body

18 points are determined as a result of intersection of a helix with a certain body. The variation series will take the following form: $t_{17}, t_{1}, t_{4}, t_{8}, t_{9}, t_{2}, t_{10}, t_{15}, t_{7}, t_{5}, t_{3}, t_{11}, t_{16}, t_{14}, t_{6}, t_{12}, t_{13}, t_{18} .8$ pairs of points are defined by grouping intersection points: $\left[t_{17}, t_{1}\right],\left[t_{4}, t_{8}\right],\left[t_{9}, t_{2}\right],\left[t_{10}, t_{15}\right],\left[t_{7}, t_{5}\right]$, $\left[t_{3}, t_{11}\right],\left[t_{16}, t_{14}\right],\left[t_{6}, t_{12}\right],\left[t_{12}, t_{18}\right]$.

Therefore, the filler is completed by the material on the spiral section corresponding to the obtained pair.

\section{Conclusion}

The model was developed to fill the internal structure of products with curved layers for 3D printing as a result of the research. The results can be applied to research in the development of algorithms and software for technological equipment, which ensures the formation of the internal structure of products by curved layers during 3D printing.

\section{References}

[1] Burns M. Automated Fabrication: Improving Productivity in Manufacturing. -Englewood Cliffs, N.J., USA: PTR Prentice Hall, 1993. - 369 pp.

[2] Improving the quality of additive methods for forming the surfaces of odd-shaped parts with the application of parallel kinematics mechanisms Kuts V.V., Razumov M.S., Grechukhin A.N., Bychkova N.A. International Journal of Applied Engineering Research. 2016. T. 11. № 24. C. 11832-11835.

[3] Dobroskok, V.L Rational orientation of products during their layer-by-layer shaping based on the initial triangulation 3d model [text] / V.L. Dobroskok, L.N. Abduraimov, S.I. Chernyshov // Scientific notes of the Crimean Engineering Pedagogical University. 2010. № 24. pp. 13-21. 
[4] Algorithm for dividing a three-dimensional model into layers for 3D printing I. A. Gushchin, A. R. Avdeev, A. A. Shvets, A.V. Drobotov//News of TulSU. Technical sciences. 2016. Issue 11. Part 2. pp 99-105.

[5] Optimum part deposition orientation in stereolithography / S. K. Singhal, A. P. Pandey, P. M. Pandey, A. K. Nagpal // Computer-Aided Design \& Applications. - 2005. - Vol. 2. - Nos. 14. - P. 319-328. https://doi.org/10.1080/16864360.2005.10738380

[6] Hong S. Byun. Determination of optimal build direction in rapid prototyping with variable slicing / Hong S. Byun, Kwan H. Lee // Int. J. Adv. Manuf. Technol. - 2006. - №. 28. - P. 307313. https://doi.org/10.1007/s00170-004-2355-5

[7] Lan P.T. Determining fabrication orientations for rapid prototyping with stereolithography apparatus / S. Y. Chou, L. L. Chent, D. Gemmill // Computer- Aided Design. - 1997. - Vol. 29. - № 1. - P. 53- 62. https://doi.org/10.1016/S0010-4485(96)00049-8

[8] Massod S. H. A generic algorithm for part orientation system for complex parts in rapid prototyping / S. H. Massod, W. Rattanawong, P. Iovenitti // J. Mater. Process. Technol. - 2003. Vol. 139. - № 1-3. - P. 110-116. https://doi.org/10.1016/S0924-0136(03)00190-0

[9] Masood S. H. A generic part orientation system based on volumetric error in rapid prototyping / S. H. Masood, W. Rattanawong // Int. J. Adv. Manuf. Technol. - 2002. - № 19. P. 209-216. https://doi.org/10.1007/s001700200015

[10] Kuts V.V, Grechukhin A.N, Olesitsky A.V and others Algorithm for dividing a volume model into curvilinear layers for 3D printing, Fundamental and applied problems of engineering and technology 2021, pp 22-27.

[11] Grechukhin A.N, Kuts V.V, Razumov M.S and others Improving the accuracy of additive forming methods Innovation, quality and service in engineering and technology, 2018, pp 128131.

[12] Grechukhin A.N, Kuts V.V, Razumov M.S Control of spatial orientation of robot units in the process of additive forming of products Bulletin of Voronezh state technical University, 2018, 4 pp 122-129.

[13] Grechukhin A.N, Kuts V.V, Razumov M.S Experimental determination of the crosssection parameters of a single layer in the additive forming products News of Tula state University. Technical science, 2019, 10 pp 264-270.

[14] Grechukhin A.N, Anikutin I.S, Byshkin A.S Management of space orientation of the end effector of generation of geometry system fiveaxis manufacturing machinery for additive generation of geometry MATEC Web of Conferences, 2018 Vol 7 pp 128-136 DOI 10.1051/matecconf/201822601004.

[15] Grechukhin A.N, Kuts V.V, Razumov M.S Ways to reduce the error of additive methods of forming - 2018 MATEC Web of Conferences Vol 7 pp142-150.

https://doi.org/10.1051/matecconf/201822601002

[16] Grechukhin, A.N, Kuts, V.V, Oleshitskiy, A.V Development and Research of Technological Equipment that Implements Dynamic Control of Process of Additive Fabrication of Parts of Complex Spatial Shapes Based on Mechanisms with a Hybrid Layout. IOP 
Conference Series: Materials Science and Engineering, 2020, 709(3), 033112. https://doi.org/10.1088/1757-899X/709/3/033112

[17] Kuts, V.V., Merkulov, V.S., Grechukhin, A.N., Privalov, A.S Investigation of the process of additive formation of fusible materials using a low-power solid-state laser. IOP Conference Series: Materials Science and Engineering, 2021, 1029(1), 012010. https://doi.org/10.1088/1757899X/1029/1/012010

[18] Grechukhin, A.N., Kuts, V.V., Razumov, M.S Solving Problem of Curved Surface Approximation by Layers with Constant and Variable Sections During Forming by Additive Methods. Lecture Notes in Mechanical Engineering, 2020, pp. 239-248.

https://doi.org/10.1007/978-3-030-22041-9_28

[19] Grechukhin, A.N., Kuts, V.V., Oleshitsky, A.V Control additive error of morphogenesis with the use of hybrid layout. AIP Conference Proceedings, 2019, 2188, 020003.

https://doi.org/10.1063/1.5138377

[20] Grechukhin, A.N., Privalov, A.S., Garkavtseva, P.A. Experimental studies of the process of additive electric arc forming in the environment of protective gases AIP Conference Proceedings, 2019, 2188, 020004. https://doi.org/10.1063/1.5138378

[21] Grechukhin, A.N., Kuts, V.V., Oleshitsky, A.V. Control of geometrical parameters of a single layer at additive forming of products by FDM technology. IOP Conference Series: Materials Science and Engineering, 2019, 680(1), 012004. https://doi.org/10.1088/1757899X/680/1/012004

[22] Grechukhin, A.N., Kuts, V.V., Razumov, M.S Calculation of the controlled parameters of the 6-coordinate robot in the process of additive forming of products. Journal of Physics: Conference Series, 2019, 1210(1), 012053. https://doi.org/10.1088/1742-6596/1210/1/012053

[23] Information on http://cyber-code.ru/tochka_v_treugolnike/ 